Argonne National Laboratory

9700 South Cass Avenue

Argonne, IL 60439

\author{
DEVELOPMENT OF MIXED-WASTE ANALYSIS CAPABILITY FOR \\ GRAPHITE FURNACE ATOMIC ABSORPTION SPECTROPHOTOMETRY \\ by \\ Dean A. Bass, Lynn B. TenKate, and Anna Wroblewski* \\ Analytical Chemistry Laboratory \\ Chemical Technology Division
}

March 1995

* Student from Illinois Benedictine College, Lisle, IL; Summer 1994 Student Research Participation Program, coordinated by the ANL Department of Educational Programs.

IT DISTRBBUTION OF THIS DOCUMENT IS UNLMMTED 


\section{TABLE OF CONTENTS}

\section{Page}

ABSTRACT 1

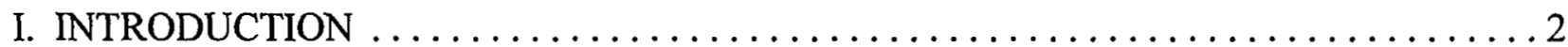

II. CONTAINMENT APPARATUS DESIGN $\ldots \ldots \ldots \ldots \ldots \ldots \ldots \ldots \ldots \ldots \ldots$

III. RESULTS AND DISCUSSION $\ldots \ldots \ldots \ldots \ldots \ldots \ldots \ldots \ldots \ldots \ldots \ldots \ldots \ldots \ldots \ldots \ldots \ldots \ldots$

A. Determination of Dispersible Radioactivity $\ldots \ldots \ldots \ldots \ldots \ldots \ldots \ldots$

B. Calculation of Allowed Sample Activity $\ldots \ldots \ldots \ldots \ldots \ldots \ldots \ldots$

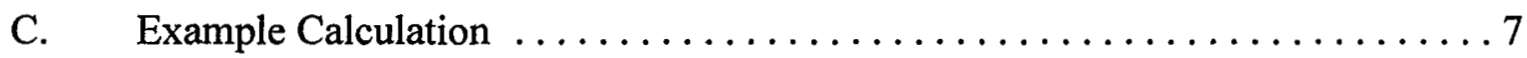

D. Determination of Instrument Performance $\ldots \ldots \ldots \ldots \ldots \ldots \ldots$

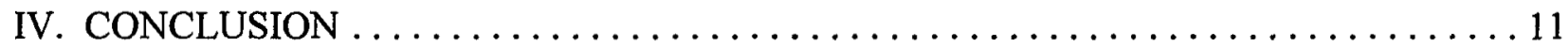

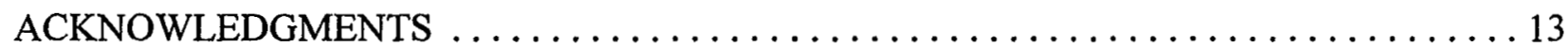

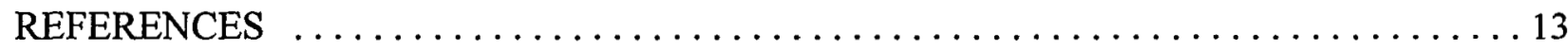




\section{LIST OF FIGURES}

No. Title

Page

1. Graphite Furnace Configuration before Modification $\ldots \ldots \ldots \ldots \ldots \ldots \ldots$

2. Schematic Drawing of Containment Apparatus . . . . . . . . . . . . . 15

3. Sliding Door and Rail Configuration $\ldots \ldots \ldots \ldots \ldots \ldots \ldots \ldots \ldots \ldots \ldots \ldots \ldots \ldots \ldots \ldots \ldots$

4. Graphite Furnace with Containment Apparatus . .................. 16

\section{LIST OF TABLES}

No.

Title

Page



2. Results from Detection Limit Determination $\ldots \ldots \ldots \ldots \ldots \ldots \ldots \ldots$

3. Summary of Instrument Performance for Lead $\ldots \ldots \ldots \ldots \ldots \ldots \ldots \ldots$ 


\title{
DEVELOPMENT OF MIXED-WASTE ANALYSIS CAPABILITY FOR GRAPHITE FURNACE ATOMIC ABSORPTION SPECTROPHOTOMETRY
}

by

Dean A. Bass, Lynn B. TenKate, and Anna Wroblewski

\begin{abstract}
Graphite furnace atomic absorption spectrophotometers (GFAAS) are typically configured with ventilation to capture potentially toxic and corrosive gases emitted from the vaporization of sample aliquots. When radioactive elements are present, additional concerns (such as meeting safety guidelines and ALARA principles) must be addressed. This report describes a modification to a GFAAS that provides additional containment of vaporized sample aliquots. The modification was found to increase containment by a factor of 80 , given expected operating conditions. The use of the modification allows more mixed-waste samples to be analyzed, permits higher levels of radioactive samples to be analyzed, or exposes the analyst to less airborne radioactivity. The containment apparatus was attached to a Perkin-Elmer Zeeman 5000 spectrophotometer for analysis of mixed-waste samples; however, it could also be used on other systems and in other applications where greater containment of vaporized material is desired.
\end{abstract}




\section{INTRODUCTION}

The U.S. Department of Energy (DOE) is projecting the need for increased capacity to analyze mixed (radiological and hazardous) waste samples [1]. Many of these analyses will involve the determination of toxic metals. The U.S. Environmental Protection Agency (EPA) generally prescribes using graphite furnace atomic absorption spectrophotometry (GFAAS) for toxic metals when inductively coupled plasma-atomic emission spectroscopy (ICP-AES) does not offer sufficient sensitivity [2]. Such toxic metals include $\mathrm{As}, \mathrm{Pb}, \mathrm{Se}$, and $\mathrm{Tl}$ but can also include $\mathrm{Sb}$ and $\mathrm{Ag}$ if the ICP-AES detection limits are not sufficiently low. Use of GFAAS is also advantageous in working with mixed wastes in that smaller quantities of sample can be used.

Graphite furnace atomic absorption spectrophotometers are typically configured with ventilation (see Fig. 1) to capture potentially toxic and corrosive gases emitted from the vaporization of sample aliquots (typically $20 \mu \mathrm{L}$ ). When radioactive elements are present, additional concerns, such as meeting safety guidelines and ALARA principles, must be addressed.

This report describes a modification to a GFAAS that provides additional containment of vaporized sample aliquots. The modification is a containment attachment for a Perkin-Elmer Model 5000 atomic absorption spectrophotometer with Zeeman background correction and an HGA-400 graphite furnace and AS-40 auto-sampler. With minor modification, this attachment could be applied to any Perkin-Elmer Model 5000 or 5100 atomic absorption spectrophotometer. This design could be applied to other GFAAS instrumentation.

We calculated the level of allowed radioactivity of ${ }^{239} \mathrm{Pu}$ in a given sample for the modified system under specified conditions. These calculations took into account requirements for work with radioactive materials as described by the Argonne National Laboratory [3]. Also, 
performance of the modified GFAAS was monitored to assure that no compromise in operating conditions had occurred. Parameters such as light throughput, measurement reproducibility, and calibration curve linearity were considered.

\section{CONTAINMENT APPARATUS DESIGN}

A Perkin-Elmer Model 5000 atomic absorption spectrophotometer with Zeeman background correction and an HGA-400 graphite furnace and AS-40 auto-sampler was modified with a containment apparatus that allows analysis of low level radioactive samples. A schematic of the apparatus is shown in Fig. 2. The containment apparatus is constructed from $1 / 4$ in. thick Plexiglas, according to the design specifications illustrated in Fig. 2, and encloses the furnace and the auto-sampler. The top front is equipped with a sliding door, which may be adjusted to control the air flow, similar to the functioning of a conventional hood. This door allows access to the samples and furnace components when necessary. Rails are bolted to the top edges of the left and right side panels to hold the sliding door. Figure 3 illustrates the rail construction. The top panel includes a hole (see A in Fig. 2) to allow for attachment of the containment housing to the ventilation duct. The air from the containment apparatus is HEPA filtered. The bottom panel contains a cut-out (see C in Fig. 2) to allow space for the instrument electrical cable and drainage hoses. The panels are connected by tapping into the ends of the Plexiglas. The panels are attached with screws. The containment apparatus is attached to the instrument by placing screws through the left and top panels into holes drilled in the instrument panels. Additional support brackets are attached to the laboratory bench and used to take some of the weight of the attachment off the instrument panels. Before this support was placed under the attachment, a reduction in light throughput was observed, as determined by the energy level from a lead electrodeless discharge lamp (EDL) before and after the attachment was installed. The energy 
level could be returned to the original value by lifting on the front of the attachment. Installing the brackets on the bench, to support the attachment, returned the energy level (and hence the light throughput) to the original value. Figure 4 shows the completed modification.

Note that the positioning of the ventilation duct restricted the opening of the sliding door to six inches. This allows sufficient access to the auto-sampler and limited access to the furnace work head. The furnace work head can be more easily accessed by removing the rails and sliding door. A design modification (e.g., changing the angle on the duct that enters the attachment) could allow the sliding door to be opened to about twelve inches without removing the rails and sliding door.

\section{RESULTS AND DISCUSSION}

\section{A. Determination of Dispersible Radioactivity}

Argonne National Laboratory's Environment, Safety, and Health Manual [3] outlines containment requirements for work with dispersible radioactive materials. These requirements are defined for specific radionuclides by the following equation:

$$
0.02 C_{D A C}=\frac{f_{a} f_{r} q}{2000 V \lambda_{v}}
$$

where

$\mathrm{C}_{\mathrm{DAC}}=$ the derived air concentration (DAC) for the specified radionuclide in $\mu \mathrm{Ci} / \mathrm{cm}^{3}$,

$0.02 \mathrm{C}_{\mathrm{DAC}}=2 \%$ of a DAC, the Argonne National Laboratory limit for work with dispersible radioactive materials,

$\mathrm{f}_{\mathrm{a}} \quad=$ escape fraction (maximum fraction of airborne material that could escape a properly operating containment system), 
$\mathrm{f}_{\mathrm{r}}=$ fraction of material that could potentially become airborne inside the containment system over a period of $2000 \mathrm{~h}$,

$\mathrm{q}=\quad=$ total activity of dispersible material in $\mu \mathrm{Ci}$,

$2000=$ number of hours in a work year (the maximum number of hours a person would be continuously exposed to airborne activity as a result of work with dispersible materials),

$\mathrm{V}=$ volume of laboratory room in $\mathrm{cm}^{3}$, and

$\lambda_{v}=$ effective number of air exchanges per hour $\left(h^{-1}\right)$.

The effective number of air exchanges, $\lambda_{\mathrm{v}}$, is obtained by multiplying the number of nominal air exchanges with a correction factor called a "mixing factor." This correction is needed because perfect mixing of air, even in small enclosures, is usually unattainable. This equation assumes that a mixing factor of $1 / 10$ is realistic for laboratory rooms, although this could vary from $1 / 3$ to $1 / 10$ (depending on the size of the room). If the number of nominal air exchanges is 6 per hour and the mixing factor is $1 / 10$, then the effective number of air exchanges is 0.6 per hour.

Values of $f_{a}$ and $f_{r}$ that might be used in the containment equation include the following:

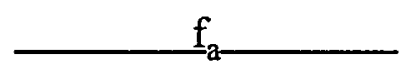

1 for benchtop work $10^{-2}$ to $10^{-3}$ for hoods $10^{-6}$ to $10^{-8}$ for gloveboxes



1 for volatiles $10^{-1}$ to $10^{-2}$ for powders $10^{-2}$ to $10^{-3}$ for liquids

From Eq. 1, we can determine the level of activity and the number of samples at that level that can be run per year (see "Calculation of Allowed Sample Activity). For a normal GFAAS, uncertainties in the capture efficiency would require the estimated escape fraction $\left(f_{a}\right)$ to be 1 . By designing and installing a containment attachment to the GFAAS, the escape fraction will be $10^{-2}$ or better. 


\section{B. Calculation of Allowed Sample Activity}

To estimate the maximum activity allowed in a sample for analysis by GFAAS, several assumptions and estimations are made. Because $\mathrm{C}_{\mathrm{DAC}}$ in Eq. 1 is per year, the time that the analyst would be exposed to the vaporized injections must be estimated. This instrument could be used to analyze about 100 samples per year, which would involve about 600 injections of 20 $\mu \mathrm{L}$ each. An exposure of one minute per vaporized $20 \mu \mathrm{L}$ injection would be a total of $600 \mathrm{~min}$ (or $10 \mathrm{~h}$ ) exposure.

During a GFAAS analysis, approximately $2 \mathrm{~mL}$ of sample (in liquid form) is poured into an open sampling cup, from which the $20 \mu \mathrm{L}$ aliquot is taken. During this time, the $2 \mathrm{~mL}$ sample would be in the open laboratory for about $1 \mathrm{~min}$ and in the containment apparatus for about $6 \mathrm{~h}$. For the 100 samples analyzed per year, this represents $100 \min$ (about $2 \mathrm{~h}$ ) in the open laboratory and $600 \mathrm{~h}$ in the containment apparatus. For a typical sample size of $200 \mathrm{~mL}$, the $20 \mu \mathrm{L}$ aliquot would represent $1 / 10000$ of the total radioactivity in the sample, and each of the $2 \mathrm{~mL}$ aliquots would represent $1 / 100$ of the radioactivity.

The three sources of dispersible radioactive material are the $20 \mu \mathrm{L}$ aliquot, the $2 \mathrm{~mL}$ sample on the benchtop, and the same $2 \mathrm{~mL}$ sample in the auto-sampler (in the containment apparatus). They are summed as follows:

$$
\begin{aligned}
0.02 C_{D A C}= & (10 / 2000)(1 / 10000)\left[\frac{f_{a 1} f_{r 1} q}{2000 V \lambda_{V}}\right]_{\text {Vaporzed Injection }} \\
& +(2 / 2000)(1 / 100)\left[\frac{f_{a 2} f_{r 2} q}{2000 V \lambda_{V}}\right]_{\text {Sample - benchtop }} \\
& +(600 / 2000)(1 / 100)\left[\frac{f_{a 1} f_{r 2} q}{2000 V \lambda_{V}}\right]_{\text {Sample - contatinment apparatus }}
\end{aligned}
$$


If we take

$$
\begin{aligned}
& \lambda_{\mathrm{v}}=0.6 \mathrm{~h}^{-1} \\
& \mathrm{~V}=1.5 \times 10^{8} \mathrm{~cm}^{3}(20 \times 27 \times 10 \mathrm{ft}) \\
& \mathrm{f}_{\mathrm{al}}=10^{-2} \text { (escape fraction in a hood) } \\
& \mathrm{f}_{\mathrm{r} 1}=1 \text { (fraction of material that could become airborne from a gas) } \\
& \mathrm{f}_{\mathrm{a} 2}=1 \text { (escape fraction on a benchtop) } \\
& \mathrm{f}_{\mathrm{r} 2}=10^{-2} \text { (fraction of material that could become airborne from a liquid) }
\end{aligned}
$$

then Eq. 2 reduces to the following:

$$
\begin{aligned}
3.6 \times 10^{9} C_{D A C} & =(0.001 / 200000)_{\text {Vaporized Injection }} q \\
& +(0.02 / 200000)_{\text {Sample }} \text { - benchtop } q \\
& +(0.06 / 200000)_{\text {Sample }} \text { - containment apparatus }
\end{aligned}
$$

For a typical $200 \mathrm{~mL}$ sample Eq. 3 reduces to a maximum allowed activity (q):

$$
q=9 \times 10^{15} C_{D A C}
$$

\section{Example Calculation}

We calculated that the maximum allowed activity of ${ }^{239} \mathrm{Pu}$ in a sample that can be analyzed by GFAAS both after and before the addition of the containment modification. The maximum allowed activity after the modification was calculated from Eq. 4. The $\mathrm{C}_{\mathrm{DAC}}$ for ${ }^{239} \mathrm{Pu}$ is $3 \times 10^{-12} \mu \mathrm{Ci} / \mathrm{cm}^{3}[4,5]$. This gives a maximum allowed activity of $27 \mathrm{mCi}$ after the modification. 
Before the modification, $\mathrm{f}_{\mathrm{a} 1}$ was 1 and the resonance time in the room was about twice as long, or two minutes for the vaporized sample. Given these assumptions, Eq. 3 becomes:

$$
\begin{aligned}
3.6 \times 10^{9} C_{D A C} & =(0.2 / 200000)_{\text {Vaporized Injection }} q \\
+ & (0.02 / 200000)_{\text {Sample }} \text { benchtop } q \\
& +(6 / 200000)_{\text {Sample }} \text { - containment apparatus }
\end{aligned}
$$

This equation yields $350 \mu \mathrm{Ci}$ as the maximum allowed activity before the modification. Thus, containment modification increases the allowed activity by a factor of 80 .

Comparing Eqs. 3 and 5 shows a significant change in exposure for both the vaporized sample injection and the sample in the containment apparatus. Note that several of the terms in Eqs. 3 and 5 are based on conservative estimates because better estimates are not available (Table 1). The net effect of these conservative estimates is to lower the estimated exposure both

\begin{tabular}{|c|c|}
\hline Term (equation number) & Why the Estimate is Conservative \\
\hline $\begin{array}{l}(0.2 / 200000)_{\text {Vaporized injection }} \mathrm{q} \\
\text { (first term; Eq. 5) }\end{array}$ & $\begin{array}{l}\text { Most of the vaporized sample is estimated to go } \\
\text { up the vent; therefore, the escape fraction is less } \\
\text { than one. }\end{array}$ \\
\hline $\begin{array}{l}(6 / 200000)_{\text {Sample - containment apparatus }} \mathrm{q} \\
\text { (third term; Eq. 5) }\end{array}$ & $\begin{array}{l}\text { The samples are placed in an auto-sampler that is } \\
\text { covered; therefore, the escape fraction is less than } \\
\text { one. }\end{array}$ \\
\hline $\begin{array}{l}(0.06 / 200000)_{\text {Sample - containment apparatus }} \mathrm{q} \\
\text { (third term; Eq. } 3 \text { ) }\end{array}$ & $\begin{array}{l}\text { The samples are placed in an auto-sampler that is } \\
\text { covered; therefore, the escape fraction is less than } \\
0.01 \text {. }\end{array}$ \\
\hline
\end{tabular}
before and after the modification, but more so before the modification.

Table 1. Considerations for Equations 3 and 5 


\section{Determination of Instrument Performance}

Experiments were performed to determine whether the containment apparatus significantly changes the performance of the instrument.

Once the modification was attached and connected with the house ventilation system, several observations were made. First, there was no compromise in the energy throughput of the system. A preliminary concern was that the added weight on the instrument might upset the optical alignment. A change in this alignment would reduce the light throughput from the source, thus increasing the noise and affecting the detection limit. Bench support brackets prevented changes in the optical alignment. Second, the air flow was at least 120 linear feet per minute (fpm) [36.5 linear meters per minute (mpm)], as measured at the opening on the bottom of the box (see Fig. 2). With the sliding door completely closed, the air flow was actually measured at $140 \mathrm{fpm}$ (42.6 mpm). According to Argonne National Laboratory regulations, the air flow must be at least $120 \mathrm{fpm}(36.5 \mathrm{mpm})$ in a hood, when analysts are working with radioactive materials. A damper in the ventilation duct allows for control of the ventilation through the duct. This was set so that the air flow was $300 \mathrm{fpm}(91.4 \mathrm{mpm})$ at the point where the duct is connected to the modification. The change in air flow through the furnace area could affect heating of the graphite tube or the residence time of the analyte in the tube. These changes could manifest themselves in the form of poorer measurement reproducibility and sensitivity, or nonlinear calibration curves.

The detection limits and the standard deviation of measurements were determined with lead standards. Before the modification, a three point calibration $(5,25$, and $50 \mathrm{ppb})$ was completed, along with the analysis of a lead ( $5 \mathrm{ppb}$ ) standard. The average standard deviation was determined by repetitive analysis of the $5 \mathrm{ppb}$ standard. Determining the detection limit involved measuring seven replicates of a $5 \mathrm{ppb}$ standard, with the absorbance corrected for an 
average blank absorbance. Three times the standard deviation of the seven replicates gives an estimate of the detection limit; the actual detection limit is an average of three estimates measured on nonconsecutive days. This estimate was performed twice to compare the results with the measured limit.

After the containment box was attached, the performance of the GFAAS was again assessed under safe operating conditions (the sliding door completely closed). Once we determined that the instrument was in good working condition and had obtained consistent calibrations, the detection limit was determined as described previously. To assess the instrument performance, we compared the detection limit determinations, as well as standard deviation data, to the analyses before the modification.

Calibration curves and detection limits were used to compare the performance of the GFAAS instrument before and after the modification. Calibration curves often indicate if there is a problem with an analysis and are routinely run to assess instrument conditions. For purposes of this project, the calibration curve is useful in assessing problems that might occur as a function of concentration, such as heating or furnace air-flow problems or changes. An acceptable correlation coefficient is 0.995 . Correlation coefficients on the order of 0.9997 were obtained both before and after the modification.

Detection limit measurements are also useful in that they provide a measure of both reproducibility and sensitivity. The results from the detection limit determinations are given in Table 2. Each cell in this table is the result of a series of measurements as described earlier, with the average of the three non-consecutive days shown at the bottom. The average is the actual detection limit, it characterizes the instrument performance over a span of time and takes into account variations in the instrument. The results from each trial are within EPA Contract Laboratory Procedures (CLP) guidelines for the determination of lead, which require a detection 
limit of below $3 \mathrm{ppb}$ [2]. Table 3 summarizes the results before and after the modification for calibration curves and detection limits. Detection limits are rounded to one significant figure. In all cases the instrument performed as expected.

Table 2. Results from Detection Limit Determination (standard deviation in $\mathrm{ppb}$ )

\begin{tabular}{|c|c|c|c|c|}
\hline \multirow{2}{*}{$\begin{array}{l}\text { Non- } \\
\begin{array}{l}\text { Consecutive } \\
\text { Days }\end{array}\end{array}$} & \multicolumn{2}{|c|}{ Before Modification } & \multicolumn{2}{c|}{ After Modification } \\
\cline { 2 - 5 } & Trial \#1 & Trial \#2 & Trial \#1 & Trial \#2 \\
\hline 1 & 1.67 & 3.29 & 1.40 & 0.84 \\
\hline 2 & 2.00 & 0.92 & 1.38 & 0.91 \\
\hline 3 & 1.72 & 1.13 & 1.69 & 0.57 \\
\hline Average: & 1.80 & 1.78 & 1.49 & 0.77 \\
\hline
\end{tabular}

Table 3. Summary of Instrument Performance for Lead

\begin{tabular}{|c|c|c|}
\hline & Before Modification & After Modification \\
\hline Calibration Curve & $\mathrm{r}^{2}=0.9997$ & $\mathrm{r}^{2}=0.9998$ \\
\hline Detection Limit & $2 \mathrm{ppb}$ & $1 \mathrm{ppb}$ \\
\hline
\end{tabular}

\section{CONCLUSION}

The work presented here describes a containment attachment for a Perkin-Elmer Model 5000 atomic absorption spectrophotometer with Zeeman background correction and an HGA400 graphite furnace and AS-40 auto-sampler. With minor modification this attachment could be applied to any Perkin-Elmer Model 5000 or 5100 atomic absorption spectrophotometer. Conceptually, this design could be applied to other GFAAS instrumentation. 
This attachment was designed specifically for radiological containment. Its use allows analysis of more radioactive samples, or permits the analysis of higher levels of radioactive samples, or results in lower exposures of radioactive material to the analyst. This attachment could also be used in other applications where greater containment is desired. One potential application is the analysis of biological samples, where it might be desired to reduce the odor associated with the charring of biological materials.

The data in Tables 2 and 3 demonstrate that critical functions of the instrument are not compromised by the attachment. Containment estimates were made by measuring air flow rates at openings in the attachment. (If this device is used at other facilities, estimates should be made there to make sure that the arrangement complies with facility specific requirements.) Air flow rates, in this application, can be controlled by ventilation baffles and the sliding door on the containment attachment. The estimates and levels of allowed dispersible activity address only inhalation aspects of normal operations with dispersible materials. If external radiation, nonstochastic effects, surface contamination, or other potential hazards are also of concern, these, too, must be considered when selecting the level of containment. 


\section{ACKNOWLEDGMENTS}

The authors would like to thank the following individuals who have contributed ideas or effort to this project: Donald Colby, Joseph Durica, Bert Ercoli, Dolores Geraghty, Donald Graczyk, Linda Graf, Peter Lindahl, Charlotte Sholeen, Venkateswara Veluri, Donald Sutter, and Raymond Wolson.

\section{REFERENCES}

1. Analytical Services Program Five-Year Plan, U.S. Department of Energy, Office of Environmental Restoration and Waste Management, Laboratory Management Division (1992).

2. USEPA Contract Laboratory Program Statement of Work for Inorganic Analysis, U.S. Environmental Protection Agency Report, ILMO2.0 (1992).

3. Argonne National Laboratory, Environment, Safety, and Health Manual, in preparation.

4. Limiting Values of Radionuclide Intake and Air Concentration and Dose Conversion Factors for Inhalation, Submersion, and Ingestion, Federal Guidance Report II, EPA520/1-88-020, September 1988.

5. Radiation Protection for Occupational Workers, Department of Energy Order 5480.11. 


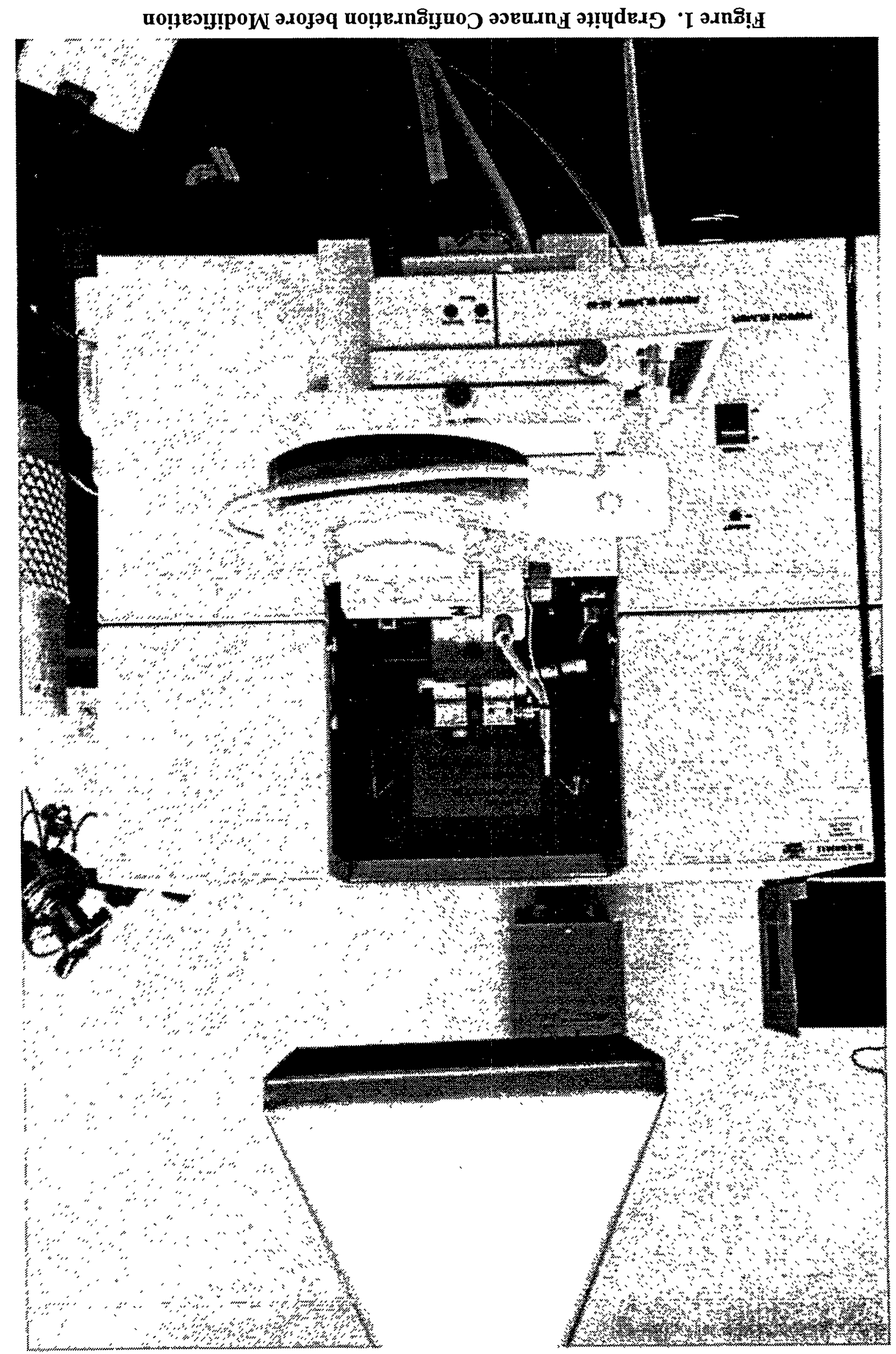






Figure 2. Schematic Drawing of Containment Apparatus 


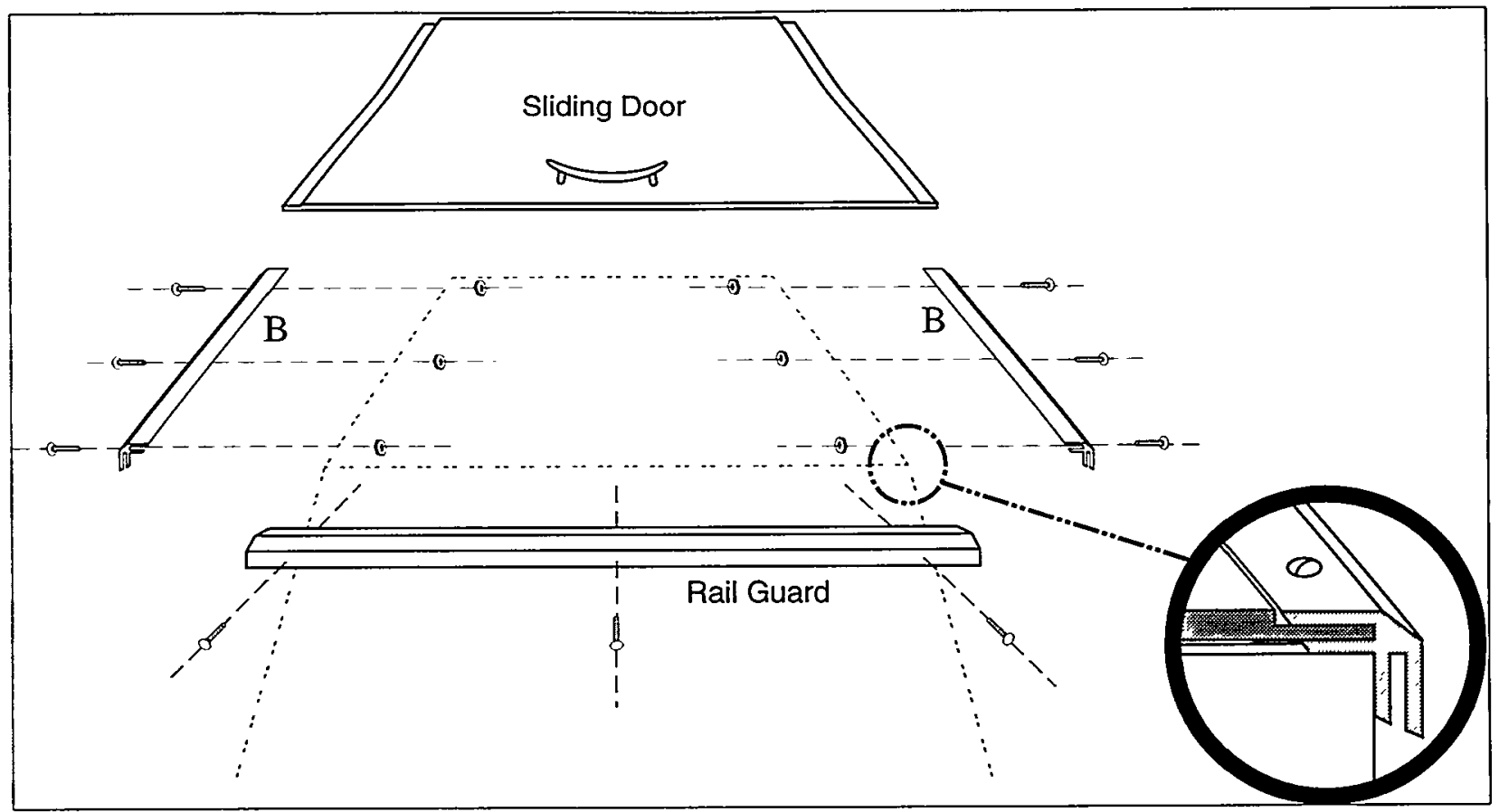

Figure 3. Sliding Door and Rail Configuration

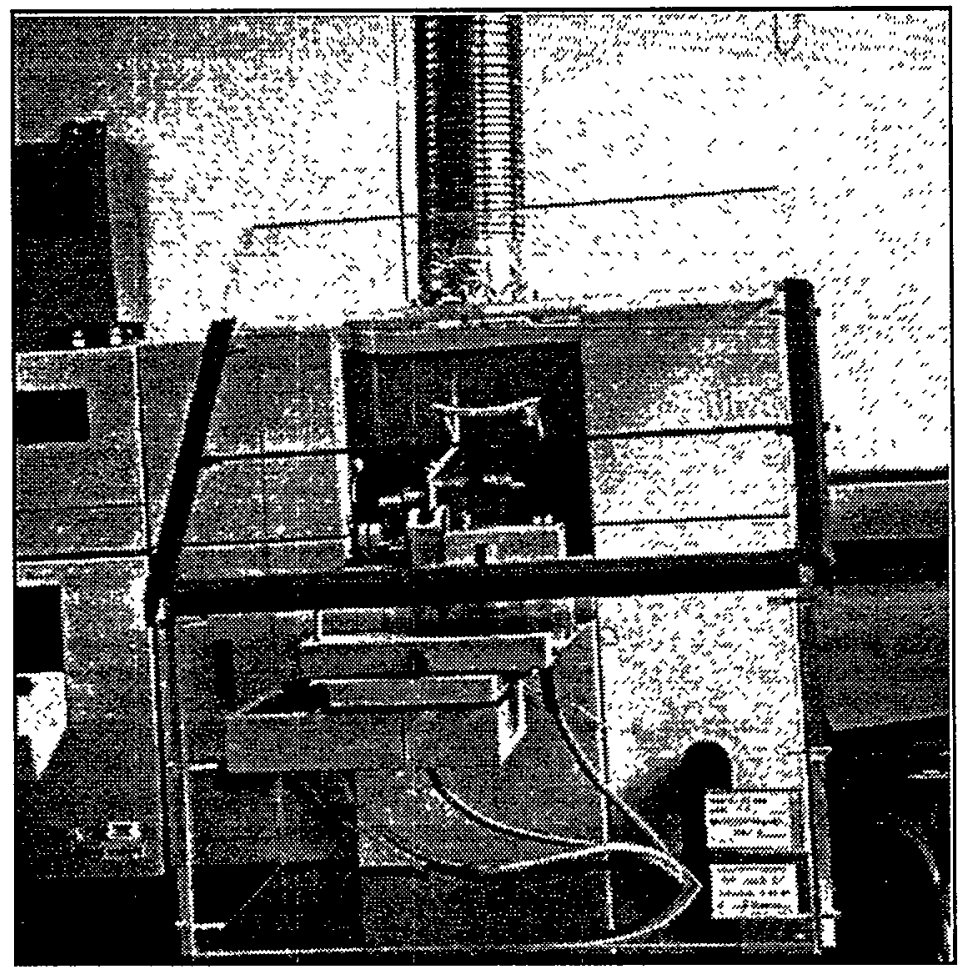

Figure 4. Graphite Furnace with Containment Apparatus 
Distribution for ANL/ACL-95/2

Internal:

I. Ahmad

O. O. Ajayi

I. Ambats

D. V. Applegate

J. G. Asbury

M. D. Atella

A. Bandopadhyaya

R. W. Bane

D. A. Bass

J. K. Bates

J. E. Battles

N. J. Beskid

M. H. Bhattacharyya

S. K. Bhattacharyya

N. Bhatti

M. Blander

D. H. Bomkamp

A. S. Boparai

D. L. Bowers

B. S. Brown

G. F. Busse

F. A. Cafasso

S. E. Carpenter

Y. I. Chang

L. L. Chromizky

D. R. Colby

R. F. Coley

J. T. Collins

J. S. Crain

E. J. Croke

J. C. Cunnane

L. W. Deitrich

J. C. Demirgian

C. B. Dennis

M. H. Derbidge

D. R. Diercks

M. L. Dietz

J. D. Ditmars

H. Drucker

F. J. Dudek

B. D. Dunlap

A. J. Dvorak
W. L. Ebert

B. Ercoli

M. D. Erickson

A. M. Essling

D. Ettinger

W. D. Fairman

F. Y. Fradin

D. Geraghty

N. W. Golchert

A. J. Goldman

D. G. Graczyk

L. Graf

J. W. Gramlich

D. W. Green

D. M. Gruen

W. H. Gunther

J. E. Harmon

D. A. Haugen

R. R. Heinrich

J. E. Helt

W. F. Henning

J. E. Herceg

I. Hlohowskyj

E. P. Horwitz

H.-S. Huang

E. Huberman

D. R. Huff

E. A. Huff

E. Y. Hwang

M. J. Janik

D. O. Johnson

P. L. Johnson

T. F. Kassner

S. D. Kent

J. T. Kiely

C. E. Klotz

A. J. Kras

A. R. Krauss

J. R. Krsul

M. Lachman

D. Larson

K. H. Leong
L. G. LeSage

M. A. Lewis

P. C. Lindahl

M. J. Lineberry

C. D. Livengood

C. D. O. Loureiro

K. S. Macal

F. Markun

V. A. Maroni

J. J. Marr

F. J. Martino

M. L. Mattox

J. R. McCreary

H. F. McFarlane

C. A. Melendres

V. A. Mendez (10)

D. E. Moncton

L. R. Morss

T. P. Mulcahey

K. M. Myles

H. W. Myron

Z. Nagy

B. W. Nashold

L. A. Neimark

P. A. Nelson

R. D. Nixon

J. W. O'Kelley

Y. Orechwa

K. J. Parish

J.-H. Park

D. C. Parzyck

T. L. Patton

C. V. Pearson

D. R. Pedersen

M. J. Pellin

M. Petrick

K. C. Picel

D. S. Poa

R. B. Poeppel

A. J. Policastro

P. D. Postlethwait

Y. L. Qian 

A. C. Raptis
R. K. Smither
A. Travelli
D. M. Ray
C. T. Snyder
Y. Tsai
G. T. Reedy
B. Srinivasan
J. P. Unik
C. A. Reilly
R. E. Stajdohar
R. A. Valentin
M. J. Robinet
V. C. Stamoudis
G. F. Vandegrift
B. J. Roop
M. J. Steindler
V. Veluri
L. E. Ross
C. M. Stevens
E. Vinokour
C. S. Sabau
L. M. Stock
D. C. Wade
N. A. Sacco-Gibson
W. E. Streets
L. C. Walters
N. F. Sather
K. Sugano
W. W. Schertz
T. G. Surles
D. W. Warren
J. B. Schilling
D. Sutter
R. M. Schletter
W. M. Swift
R. W. Weeks
A. Schriesheim
T. A. Taiwo
M. L. Wesely
W. J. Shack
B. S. Tani
J. M. Williams
G. K. Shenoy
J. D. Taylor
C. Sholeen
L. B. TenKate
R. E. Winans
R. D. Wolson
J. G. Sleeth
T. TenKate
D. L. Smith
R. J. Teunis
J. L. Woodring
D. L. Smith
C. E. Till
F. P. Smith
D. Tomasko
L. L. Smith
Z. Tomczuk
J. J. Wray
R. A. Wynveen
Y. Xie
J. S. Yaeger
R. K. Yoo
TIS Files

External:

DOE-OSTI (2)

ANL-E Library (2)

ANL-W Library

Manager, Chicago Operations Office, DOE

M. Bollinger, DOE-CH

J. Haugen, DOE-CH

R. E. Lang, DOE-CH

A. L. Taboas, DOE-CH/AAO

Chemical Technology Division Review Committee Members:

E. R. Beaver, Monsanto Company, St. Louis, MO

D. L. Douglas, Consultant, Bloomington, $M N$

R. K. Genung, Oak Ridge National Laboratory, Oak Ridge, TN

J. G. Kay, Drexel University, Philadelphia, PA

G. R. St. Pierre, Ohio State University, Columbus, $\mathrm{OH}$

J. Stringer, Electric Power Research Institute, Palo Alto, CA

J. B. Wagner, Arizona State University, Tempe, AZ

T. A. Baillieul, Battelle Columbus Laboratories, Columbus, $\mathrm{OH}$

P. Baisden, Lawrence Livermore National Laboratory, Livermore, CA

T. Beasley, U. S. Environmental Measurements Lab., New York, NY

J. Bennett, EG\&G Idaho, Inc., Idaho National Engineering Lab, Idaho Falls, ID

R. E. Berkeley, U.S. Environmental Protection Agency, Research Triangle Park, NC 
R. Bisping, Westinghouse Electric Corporation, Carlsbad, NM

J. A. Borders, Sandia National Laboratories, Albuquerque, NM

R. B. Chessmore, GEOTECH/GJPO, Grand Junction, CO

N. F. Christopher, Martin Marietta Energy Systems, Piketon, OH

G. Clark, Reynolds Electric \& Engineering, Las Vegas, NV

C. E. Coffey, LATO/Rocky Flats Plant, Golden, CO

P. T. Cunningham, Los Alamos National Laboratory, Los Alamos, NM

J. L. Daniel, Battelle Pacific Northwest Laboratory, Richland, WA

H. J. Dewey, Los Alamos National Laboratory, Los Alamos, NM

D. A. Dodd, Westinghouse Hanford Company, Richland, WA

J. G. Dorsey, Martin Marietta Energy Systems, Oak Ridge, TN

P. A. Duhamel, USDOE, Office of Health and Environmental Research, Germantown, MD

C. Elly, U. S. Environmental Protection Agency, Chicago, IL

R. B. Fitts, Oak Ridge National Laboratory, Oak Ridge, TN

I. M. Fox, Woodridge, IL

C. W. Frank, USDOE, Office of Technology Development, Washington, DC

J. Goldstein, USDOE, Office of Health and Environmental Research, Germantown, MD

T. C. Greengard, Rocky Flats Plant, Golden, CO

B. T. Gregg, Allied Signal Aerospace Company, Kansas City, MO

T. Grumbly, USDOE, Office of Environmental Management, Washington, DC

J. Harness, USDOE, Morgantown Energy Technology Center, Morgantown, WV

D. Hunter, EG\&G Rocky Flats Plant, Golden, CO

W. Killian, Ferris State University, Big Rapids, MI

A. G. King, Pacific Northwest Laboratories, Richland, WA

P. Krey, USDOE, Environmental Measurements Labs, New York, NY

C. S. Leasure, Los Alamos National Laboratory, Los Alamos, NM

L. C. Lewis, Westinghouse Idaho Nuclear Company, Idaho Falls, ID

J. Mahoney, West Valley Nuclear Services Company, West Valley, NY

S. Messenger, Morton Arboretum, Lisle, IL

R. W. Morrow, Martin Marietta Energy Systems, Oak Ridge, TN

L. Newman, Brookhaven National Laboratory, Upton, NY

R. D. Oldham, New Brunswick Laboratory, Argonne, IL

M. Pennington, Allied Signal, Kansas City, MO

J. Phillips, Los Alamos National Laboratory, Los Alamos, NM

J. D. Pleil, U.S. Environmental Protection Agency, Research Triangle Park, NC

G. D. Robbins, Martin Marietta Energy Systems, Oak Ridge, TN

C. Ross, U.S. Environmental Protection Agency, Chicago, IL

P. Russ, Lawrence Livermore National Laboratory, Livermore, CA

R. Scott, USDOE, Office of Environmental Quality, Washington, DC

J. Q. Searcy, Sandia National Laboratories, Albuquerque, NM

A. Sharma, Pacific Northwest Laboratories, Richland, WA

J. Smith, University of Chicago, Chicago, $\mathrm{L}$

W. A. Spencer, Westinghouse Savannah River Company, Aiken, SC

J. R. Stetter, Transducer Research, Inc., Naperville, IL

F. D. Stevenson, USDOE, Office of Basic Energy Sciences, Germantown, MD

C. Stroup, Westinghouse Hanford Company, Richland, WA 
L. Sygitowicz, Reynolds Electrical \& Engineering Co., Las Vegas, NV

R. Villarreal, Los Alamos National Laboratory, Los Alamos, NM

W. M. Walsh, Health Research Institute, Naperville, $\mathbb{L}$

R. J. Wingender, Dexter Corporation, Waukegan, IL

J. Zarret, EG\&G Rocky Flats Plant, Golden, CO 